\title{
Prognostic factors for elderly gastric cancer patients who underwent gastrectomy
}

\author{
Shunji Endo ${ }^{1 *} \mathbb{D}$, Tomoki Yamatsuji ${ }^{2}$, Yoshinori Fujiwara ${ }^{1}$, Masaharu Higashida' ${ }^{1}$, Hisako Kubota', \\ Hideo Matsumoto ${ }^{3}$, Hironori Tanaka', Toshimasa Okada', Kazuhiko Yoshimatsu', Ken Sugimoto ${ }^{4}$ and \\ Tomio Ueno ${ }^{1}$
}

\begin{abstract}
Background: Patients with gastric cancer are aging in Japan. It is not clear which patients and which surgical procedures have survival benefits after gastrectomy. A multivariate analysis was performed.

Methods: The medical records of 166 patients aged $\geq 80$ years who underwent gastrectomy without macroscopic residual tumors were retrospectively reviewed. Univariate and multivariate analyses using Cox proportional hazard models were performed to detect prognostic factors for overall survival.

Results: In univariate analyses, age ( $\geq 90$ vs. $\geq 80,<85$ ), performance status (3 vs. 0), American Society of Anesthesiologists physical status (ASA-PS) (3, 4 vs. 1, 2), Onodera's prognostic nutritional index ( $<40$ vs. $\geq 45$ ), the physiological score of the Physiological and Operative Severity Score for the enUmeration of Mortality and morbidity (POSSUM) $(\geq$ 40 vs. $\geq 20, \leq 29$ ), surgical approach (laparoscopic vs. open), extent of gastrectomy (total, proximal vs. distal), extent of lymphadenectomy (D1 vs. $\geq$ D2), pathological stage (II-IV vs. I), and residual tumor (R1 vs. R0) were significantly correlated with worse overall survival. Multivariate analysis revealed that ASA-PS $[3,4$ vs. 1, 2, hazard ratio (HR) 2.30, 95\% confidence interval (Cl) 1.24-4.24], extent of gastrectomy (total vs. distal, HR 2.17, 95\% Cl 1.10-4.31) (proximal vs. distal, HR 4.05, 95\% Cl 1.45-11.3), extent of lymphadenectomy (D0 vs. $\geq$ D2, HR 12.4, 95\% Cl 1.58-97.7), and pathological stage were independent risk factors for mortality.
\end{abstract}

Conclusions: ASA-PS was a useful predictor for postoperative mortality. Gastrectomy including cardia is best avoided.

Keywords: Gastric cancer, Aged, Octogenarians, Surgery, Prognostic factor

\section{Background}

The population of Japan is aging year by year. According to official Japanese statistics, 9.3\% of Japan's population was estimated to be $\geq 80$ years in 2021 [1]. With the aging trend of the population, patients with gastric cancer are also aging. According to the National Clinical Database (NCD) in Japan, the percentages of patients aged $\geq 80$ years who underwent distal and total gastrectomy

*Correspondence: shunji.endo@hosp-yao.osaka.jp

${ }^{1}$ Department of Digestive Surgery, Kawasaki Medical School, 577 Matsushima, Kurashiki, Okayama 701-0192, Japan

Full list of author information is available at the end of the article increased from $18.5 \%$ and $15.0 \%$ in 2011 to $24.0 \%$ and $20.9 \%$ in 2018 , respectively [2].

Some reports showed that the postoperative survivals were equivalent between those aged $\geq 80$ years and those aged $<80$ years [3-5], while they were worse in the former patients than in the latter patients $[6,7]$ as elderly patients have reduced physical, physiological, nutritional, and mental functions, comorbidities, and short life expectancy. Furthermore, gastrectomy may reduce oral intake and thus induce malnutrition. Treatment strategies should therefore be carefully selected in

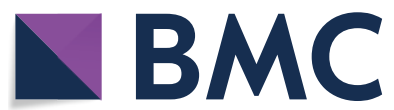

(c) The Author(s) 2022. Open Access This article is licensed under a Creative Commons Attribution 4.0 International License, which permits use, sharing, adaptation, distribution and reproduction in any medium or format, as long as you give appropriate credit to the original author(s) and the source, provide a link to the Creative Commons licence, and indicate if changes were made. The images or other third party material in this article are included in the article's Creative Commons licence, unless indicated otherwise in a credit line to the material. If material is not included in the article's Creative Commons licence and your intended use is not permitted by statutory regulation or exceeds the permitted use, you will need to obtain permission directly from the copyright holder. To view a copy of this licence, visit http://creativecommons.org/licenses/by/4.0/. The Creative Commons Public Domain Dedication waiver (http://creativeco mmons.org/publicdomain/zero/1.0/) applies to the data made available in this article, unless otherwise stated in a credit line to the data. 
consideration of their condition, symptoms, cancer stage, and social support.

Generally, Eastern Cooperative Oncology Group performance status (ECOG-PS) [8] and American Society of Anesthesiologists physical status (ASA-PS) [9] are used for preoperative risk assessment, and Onodera's prognostic nutritional index (PNI) [10] and Physiological and Operative Severity Score for the enUmeration of Mortality and morbidity (POSSUM) [11] are also reported to be useful risk predictors for gastrectomy [12, 13]. It is also recommended that extent of gastrectomy and lymphadenectomy be limited to avoid complications for elderly patients [14].

This study aimed to retrospectively investigate the prognostic factors for elderly gastric cancer patients aged $\geq 80$ years who underwent gastrectomy. The results may be helpful in predicting what characteristics and procedures are associated with better prognosis and to decide surgical indications for these patients.

\section{Methods}

\section{Patients and data retrieval}

The medical records of 112 and 65 consecutive patients aged $\geq 80$ years who underwent surgery for gastric cancer at Kawasaki Medical School Hospital between 2010 and 2019 and at Kawasaki Medical School General Medical Center between 2011 and 2019, respectively, were retrospectively reviewed. Excluding six patients who underwent R2 (macroscopic residual tumor) resection, three who underwent probe laparotomy, and two who underwent gastrojejunostomy, 166 patients who underwent R0 (curative) or R1 (microscopic residual tumor) resection were analyzed. A flowchart of the patient selection is shown in Fig. 1.

The following information was collected from the patients' medical records: age, sex, ECOG-PS score, ASA-PS classification, PNI, physiological score of POSSUM, surgical procedure, histological classification of gastric cancer, clinicopathological cancer stage, residual tumor, postoperative complications, postoperative chemotherapy, and prognosis. The effects of these preoperative characteristics, perioperative treatment, and pathological features on overall survival (OS) were evaluated by univariate and multivariate analyses. The PNI is calculated using the following formula: $10 \times$ serum albumin $(\mathrm{g} / \mathrm{dL})$ $+0.005 \times$ total lymphocyte count $\left(/ \mathrm{mm}^{3}\right)$. The POSSUM physiological score was calculated based on the patient's age, cardiac signs, chest radiography signs, respiratory history, systolic blood pressure, pulse rate, Glasgow coma scale score, hemoglobin level, white blood cell count, plasma urea level, plasma sodium level, plasma potassium level, and electrocardiography results. Each item was scored from 1 (normal) to 8 (abnormal). Adding

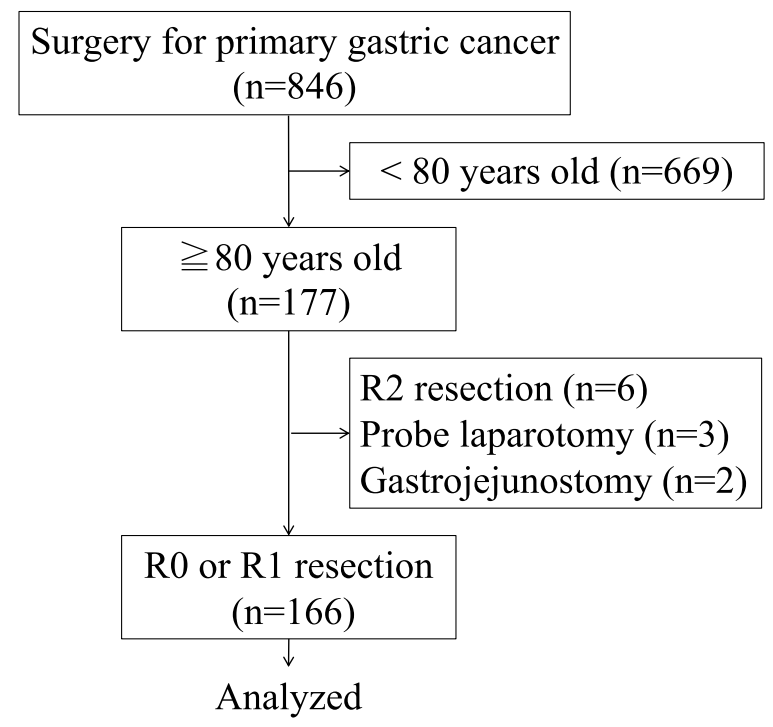

Fig. 1 The participant flow diagram. R2, macroscopic residual tumor; R1, microscopic residual tumor; RO, no residual tumor

the scores gives a physiological score ranging from a minimum of 12 to a maximum of 88 , with a higher score indicating a higher surgical risk. The clinicopathological findings of gastric cancer are recorded according to the Japanese classification of gastric carcinoma: 3rd English edition [15], and the surgical procedure and lymphadenectomy are recorded according to the Japanese Gastric Cancer Treatment Guidelines 2018 (5th edition) [16]. Prognoses including the last date known to be alive or the date and cause of death were gathered from the medical records at the participating institutions or referral institutions, the condolences sections of local newspapers, or by calling the patients or their families.

\section{Statistical analysis}

OS was defined as the interval from the date of surgery to the date of death from any cause. Surviving patients were censored at the date they were last known to be alive. Hazard ratios (HRs) for death were estimated using the Cox regression analysis. Analyses were performed using the JMP software (version 14.2.0 for Windows; SAS Institute Inc., Cary, NC, USA).

\section{Results}

The patients' characteristics are summarized in Table 1. The oldest patient in the current series was a 96-yearold male. Seventy-seven percent of participating patients were ECOG-PS 0,1, and 72\% of them were ASA-PS 1,2. The extents of gastrectomy and lymphadenectomy were limited in some cases. Proximal gastrectomy was performed in 11 patients, although seven of them were 
Table 1 Patients' characteristics

\begin{tabular}{|c|c|}
\hline \multicolumn{2}{|l|}{ Age, years } \\
\hline Median (range) & $83(80-96)$ \\
\hline \multicolumn{2}{|l|}{ Sex, $n(\%)$} \\
\hline Male & $113(68)$ \\
\hline \multicolumn{2}{|l|}{ ECOG-PS score, $n(\%)$} \\
\hline 0 & $81(49)$ \\
\hline 1 & $47(28)$ \\
\hline 2 & $28(17)$ \\
\hline 3 & $10(6)$ \\
\hline \multicolumn{2}{|l|}{ ASA-PS, $n(\%)$} \\
\hline 1 & $7(4)$ \\
\hline 2 & $112(67)$ \\
\hline 3 & $45(27)$ \\
\hline 4 & $2(1)$ \\
\hline \multicolumn{2}{|l|}{ PNI } \\
\hline Median (range) & $44.5(19.1-63.0)$ \\
\hline \multicolumn{2}{|c|}{ POSSUM physiological score } \\
\hline Median (range) & $28(20-46)$ \\
\hline \multicolumn{2}{|l|}{ Approach, $n(\%)$} \\
\hline Open & $120(72)$ \\
\hline Laparoscopic & $46(28)$ \\
\hline \multicolumn{2}{|c|}{ Extent of gastrectomy, $n(\%)$} \\
\hline Distal & $104(63)$ \\
\hline Total & $32(19)$ \\
\hline Proximal & $11(7)$ \\
\hline Local & $13(8)$ \\
\hline Completion & $5(3)$ \\
\hline Subtotal of remnant & $1(1)$ \\
\hline \multicolumn{2}{|c|}{ Extent of lymphadenectomy, $n$ (\%) } \\
\hline $\mathrm{D} 2+$ & $1(1)$ \\
\hline D2 & $38(23)$ \\
\hline $\mathrm{D} 1+$ & $73(44)$ \\
\hline D1 & $37(22)$ \\
\hline D0 & $17(10)$ \\
\hline \multicolumn{2}{|c|}{ Histological classification, $n(\%)$} \\
\hline tub & $93(56)$ \\
\hline pap & $10(6)$ \\
\hline por & $45(27)$ \\
\hline sig & $5(3)$ \\
\hline muc & $7(4)$ \\
\hline other & $6(4)$ \\
\hline \multicolumn{2}{|l|}{ pStage, n (\%) } \\
\hline $\mid A$ & $59(36)$ \\
\hline IB & $12(7)$ \\
\hline$\| \mathrm{A}$ & $30(18)$ \\
\hline$\| B$ & $19(11)$ \\
\hline$\| I A$ & $18(11)$ \\
\hline IIIB & $13(8)$ \\
\hline$\| I I C$ & $2(1)$ \\
\hline IV & $13(8)$ \\
\hline
\end{tabular}

Table 1 (continued)

\begin{tabular}{ll}
\hline Residual tumor, $n(\%)$ & $151(91)$ \\
R0 & $15(9)$ \\
R1 & \\
Postoperative chemotherapy, $n(\%)$ & $156(94)$ \\
No & $10(6)$ \\
Yes &
\end{tabular}

Pathological findings are provided according the Japanese classification of gastric carcinoma: 3rd English edition. ECOG-PS Eastern Cooperative Oncology Group Performance Status, ASA-PS American Society of Anesthesiologists physical status, PNI Onodera's prognostic nutritional index, POSSUM Physiological and Operative Severity Score for the enUmeration of Mortality and morbidity

cT2-4 and/or cN+. Local gastrectomy was selected in 13 patients, including 4, 4, and 5 patients with cT1aN0, cT1bN0, and cT2N0, respectively. Limited lymphadenectomy less than D2 was applied for 127 patients, although 70 of them were cT2-4 and/or $\mathrm{cN}+$. One hundred and fifty-one patients underwent R0 resection, while 15 patients underwent $\mathrm{R} 1$ resection including 11 patients with CY1 and five patients with positive resection margins (one patient with both CY1 and positive resection margin). After surgery, 10 patients received chemotherapy: S-1 monotherapy for nine patients $(1,1,3,2$, and 2 patients with pStage IIA, IIB, IIIA, IIIb, and IV, respectively) and S-1 plus cisplatin for one patient (pStage IV).

Postoperative complications of grade II or worse according to the Clavien-Dindo classification [17] were detected during hospitalization in 45 patients (27\%). Details of the surgical and medical complications are shown in Table 2. Anastomotic leakage $(n=6,3.6 \%)$ and abscess $(n=6)$ were the most common surgical complications and resulted in death for one patient each. Pneumonia ( $n=10,6.0 \%)$ and other respiratory failure ( $n=5,3.0 \%$ ) were the most and second most common medical complications, respectively. Eight such patients needed mechanical ventilation, and two died during hospitalization.

At the time of analysis, 72 patients had died. The causes of death are shown in Table 3. The leading cause of death was gastric cancer (37\% of known cause), followed by pneumonia (21\%), stroke (11\%) and senility (11\%). The median OS time was 62.3 months and the 5-year OS rate was $51.4 \%$.

In univariate analyses, age ( $\geq 90$ vs. $\geq 80,<85$ ), ECOGPS (3 vs. 0 ), ASA-PS (3, 4 vs. 1,2$)$, PNI (<40 vs. $\geq 45$ ), POSSUM physiological score ( $\geq 40$ vs. $\geq 20, \leq 29$ ), surgical approach (laparoscopic vs. open), extent of gastrectomy [total (including completion gastrectomy), proximal vs. distal (including subtotal resection of remnant stomach)], extent of lymphadenectomy (D1 vs. $\geq$ D2), pathological stage (II-IV vs. I), and residual tumor 
Table 2 Postoperative complications $\geq$ Clavien-Dindo II

\begin{tabular}{|c|c|c|c|c|c|c|c|}
\hline & \multirow[t]{2}{*}{ Total } & \multicolumn{6}{|c|}{ Clavien-Dindo } \\
\hline & & II & IIIA & IIIB & IVA & IVB & v \\
\hline Surgical complications & 20 & & & & & & \\
\hline Anastomotic leakage & 6 & 3 & 1 & & 1 & & 1 \\
\hline Anastomotic bleeding & 1 & 1 & & & & & \\
\hline Anastomotic stenosis & 1 & 1 & & & & & \\
\hline Pancreatic fistula & 4 & 1 & 2 & 1 & & & \\
\hline Abscess & 6 & 2 & 2 & & & 1 & 1 \\
\hline Bowel obstruction & 1 & & & 1 & & & \\
\hline Wound dehiscence & 1 & & & 1 & & & \\
\hline Medical complications & 30 & & & & & & \\
\hline Stroke & 4 & 3 & & & & & 1 \\
\hline Myoclonus & 1 & 1 & & & & & \\
\hline Supraventricular arrhythmia & 3 & 3 & & & & & \\
\hline Ischemic heart disease & 1 & 1 & & & & & \\
\hline Pneumonia & 10 & 6 & & & 2 & & 2 \\
\hline Other respiratory failure & 5 & & 1 & & 4 & & \\
\hline Pleural effusion & 2 & & 2 & & & & \\
\hline Pseudomembranous colitis & 2 & 2 & & & & & \\
\hline Liver damage & 2 & 2 & & & & & \\
\hline Influenza infection & 1 & 1 & & & & & \\
\hline Urinary tract infection & 2 & 2 & & & & & \\
\hline Sepsis & 1 & & & & & & 1 \\
\hline No & 121 & & & & & & \\
\hline
\end{tabular}

The total number of complications and patients do not match because some patients had multiple complications

Table 3 Cause of death

\begin{tabular}{ll}
\hline Variable & $(\boldsymbol{n}=\mathbf{7 2})$ \\
\hline Gastric cancer & 24 \\
Surgical complication & 2 \\
Stroke & 7 \\
Cardiovascular disease & 4 \\
Pneumonia & 14 \\
Other respiratory disease & 2 \\
Bowel obstruction & 1 \\
Other malignancy & 3 \\
Trauma & 1 \\
Senility & 7 \\
Unknown cause & 7 \\
\hline
\end{tabular}

(R1 vs. R0) were significantly correlated with worse OS (Table 4). Multivariate analysis conducted with these significant factors of age, ECOG-PS, ASA-PS, PNI, POSSUM physiological score, surgical approach, extent of gastrectomy, extent of lymphadenectomy, pathological stage, and residual tumor revealed that ASA-PS (3,4 vs. $1,2)$, extent of gastrectomy (total, proximal vs. distal), extent of lymphadenectomy (D0 vs. $\geq$ D2), and pathological stage (II-IV vs. I) were independent risk factors for mortality.

\section{Discussion}

In the current retrospective study, we analyzed the surgical outcomes of 166 consecutive patients aged $\geq 80$ years with gastric cancer who underwent gastrectomy with curative intent in two institutions. Most of the participants were in relatively good general condition, which may mean that only selected patients underwent surgery. The extents of gastrectomy and lymphadenectomy were often limited. The incidence of postoperative respiratory complications including pneumonia was high, and complications were likely to become serious. Pneumonia was the second leading cause of death following gastric cancer. Univariate analyses showed that extremely advanced age ( $\geq 90$ years), worse general, physical, nutritional, or physiological condition (ECOG-PS 3, ASA-PS 3,4, PNI $<40$, POSSUM physiological score $\geq 40$ ), open surgery, total or proximal gastrectomy, D1 lymphadenectomy, advanced cancer stage (pStage II-IV), and R1 resection were prognostic factors for worse OS. A multivariate 
Table 4 Univariate and multivariate analyses of hazard ratios for death

\begin{tabular}{|c|c|c|c|c|c|c|c|c|}
\hline \multirow[t]{2}{*}{ Valuables } & \multirow[t]{2}{*}{$n$} & \multirow[t]{2}{*}{ MST (months) } & \multicolumn{3}{|c|}{ Univariate analysis } & \multicolumn{3}{|c|}{ Multivariate analysis } \\
\hline & & & HR & $(95 \% \mathrm{Cl})$ & $p$ & HR & $(95 \% \mathrm{Cl})$ & $p$ \\
\hline \multicolumn{9}{|l|}{ Age (year) } \\
\hline$\geq 80,<84$ & 101 & $>120$ & Reference & & & Reference & & \\
\hline$\geq 85,<89$ & 53 & 77.5 & 1.16 & $(0.68-1.96)$ & 0.59 & 0.89 & $(0.49-1.65)$ & 0.72 \\
\hline$\geq 90$ & 12 & 29.7 & 2.55 & $(1.30-5.00)$ & $<0.01$ & 2.09 & $(0.87-5.03)$ & 0.10 \\
\hline \multicolumn{9}{|l|}{ Sex } \\
\hline Male & 113 & 62.3 & Reference & & & & & \\
\hline Female & 53 & $>109$ & 1.04 & $(0.63-1.71)$ & 0.89 & & & \\
\hline \multicolumn{9}{|l|}{ ECOG-PS } \\
\hline 0 & 81 & 85.9 & Reference & & & Reference & & \\
\hline 1 & 47 & 48.5 & 1.25 & $(0.71-2.21)$ & 0.44 & 0.85 & $(0.44-1.65)$ & 0.64 \\
\hline 2 & 28 & 28.7 & 1.74 & $(0.94-3.25)$ & 0.08 & 1.54 & $(0.75-3.15)$ & 0.24 \\
\hline 3 & 10 & 14.9 & 3.75 & $(1.62-8.67)$ & $<0.01$ & 1.44 & $(0.47-4.38)$ & 0.52 \\
\hline \multicolumn{9}{|l|}{ ASA-PS } \\
\hline 1,2 & 118 & 85.9 & Reference & & & Reference & & \\
\hline 3,4 & 47 & 20.8 & 2.60 & $(1.58-4.28)$ & $<0.01$ & 2.30 & $(1.24-4.27)$ & $<0.01$ \\
\hline \multicolumn{9}{|l|}{ PNI } \\
\hline$\geq 45$ & 77 & $>120$ & Reference & & & Reference & & \\
\hline$\geq 40,<45$ & 35 & 77.5 & 1.52 & $(0.80-2.91)$ & 0.20 & 1.82 & $(0.87-3.79)$ & 0.11 \\
\hline$<40$ & 53 & 22.7 & 2.62 & $(1.54-4.45)$ & $<0.01$ & 1.39 & $(0.68-2.86)$ & 0.36 \\
\hline \multicolumn{9}{|l|}{ POSSUM physiological score } \\
\hline$\geq 20, \leq 29$ & 99 & 79.2 & Reference & & & Reference & & \\
\hline$\geq 30, \leq 39$ & 56 & 54.0 & 1.13 & $(0.68-1.88)$ & 0.63 & 0.68 & $(0.38-1.20)$ & 0.18 \\
\hline$\geq 40$ & 11 & 6.7 & 3.95 & $(1.89-8.24)$ & $<0.01$ & 2.00 & $(0.78-5.16)$ & 0.15 \\
\hline \multicolumn{9}{|l|}{ Cardiac signs and chest radiography signs } \\
\hline No failure & 34 & 70.2 & Reference & & & & & \\
\hline Diuretic, digoxin, antianginal or hypertensive therapy & 61 & 55.6 & 1.06 & $(0.57-1.98)$ & 0.85 & & & \\
\hline $\begin{array}{l}\text { Peripheral edema, warfarin therapy, borderline cardio- } \\
\text { megaly }\end{array}$ & 60 & 74.1 & 1.03 & $(0.55-1.94)$ & 0.93 & & & \\
\hline Raised jugular venous pressure, cardiomegaly & 11 & 36.6 & 1.64 & $(0.63-4.27)$ & 0.31 & & & \\
\hline \multicolumn{9}{|l|}{ Respiratory history } \\
\hline No dyspnea & 69 & 51.2 & Reference & & & & & \\
\hline Dyspnea on exertion, mild COPD & 75 & 86.7 & 0.69 & $(0.42-1.13)$ & 0.14 & & & \\
\hline Limiting dyspnea, moderate COPD & 9 & 29.7 & 2.18 & $(1.00-4.76)$ & 0.05 & & & \\
\hline Dyspnea at rest, fibrosis or consolidation & 13 & 24.3 & 2.13 & $(0.93-4.88)$ & 0.07 & & & \\
\hline \multicolumn{9}{|l|}{ Surgical approach } \\
\hline Open & 120 & 40.2 & Reference & & & Reference & & \\
\hline Laparoscopic & 46 & 85.9 & 0.45 & $(0.25-0.82)$ & $<0.01$ & 1.58 & $(0.64-3.89)$ & 0.32 \\
\hline \multicolumn{9}{|l|}{ Extent of gastrectomy } \\
\hline Distal $^{a}$ & 105 & 85.9 & Reference & & & Reference & & \\
\hline Total $^{b}$ & 37 & 20.8 & 2.40 & $(1.42-4.05)$ & $<0.01$ & 2.17 & $(1.10-4.31)$ & 0.03 \\
\hline Proximal & 11 & 29.3 & 2.31 & $(1.07-4.99)$ & 0.03 & 4.05 & $(1.45-11.3)$ & $<0.01$ \\
\hline Local & 13 & $>97.6$ & 0.79 & $(0.31-2.02)$ & 0.62 & 0.08 & $(0.01-0.90)$ & 0.04 \\
\hline \multicolumn{9}{|l|}{ Extent of lymphadenectomy } \\
\hline$\geq \mathrm{D} 2$ & 39 & $>120$ & Reference & & & Reference & & \\
\hline $\mathrm{D} 1+$ & 73 & 77.5 & 1.20 & $(0.62-2.33)$ & 0.58 & 1.42 & $(0.66-3.04)$ & 0.37 \\
\hline D1 & 37 & 22.4 & 2.56 & $(1.30-5.04)$ & $<0.01$ & 2.00 & $(0.90-4.41)$ & 0.09 \\
\hline D0 & 17 & 62.3 & 1.13 & $(0.45-2.84)$ & 0.80 & 12.4 & $(1.58-97.7)$ & 0.02 \\
\hline
\end{tabular}


Table 4 (continued)

\begin{tabular}{|c|c|c|c|c|c|c|c|c|}
\hline \multirow[t]{2}{*}{ Valuables } & \multirow[t]{2}{*}{$n$} & \multirow[t]{2}{*}{ MST (months) } & \multicolumn{3}{|c|}{ Univariate analysis } & \multicolumn{3}{|c|}{ Multivariate analysis } \\
\hline & & & HR & $(95 \% \mathrm{Cl})$ & $p$ & HR & $(95 \% \mathrm{Cl})$ & $p$ \\
\hline \multicolumn{9}{|c|}{ Histological classification } \\
\hline tub,pap & 103 & 77.5 & Reference & & & & & \\
\hline pos,sig & 50 & 28.6 & 1.63 & $(0.99-2.68)$ & 0.05 & & & \\
\hline other & 13 & $>109$ & 0.95 & $(0.38-2.41)$ & 0.91 & & & \\
\hline \multicolumn{9}{|l|}{ pStage } \\
\hline । & 71 & 85.9 & Reference & & & Reference & & \\
\hline$\|$ & 49 & 48.5 & 2.00 & $(1.09-3.67)$ & 0.03 & 2.39 & $(1.03-5.56)$ & 0.04 \\
\hline III & 33 & 20.8 & 3.16 & $(1.68-5.95)$ & $<0.01$ & 3.03 & $(1.24-7.40)$ & 0.02 \\
\hline IV & 13 & 6.1 & 9.93 & $(4.45-22.2)$ & $<0.01$ & 5.44 & $(1.17-25.4)$ & 0.03 \\
\hline \multicolumn{9}{|c|}{ Residual tumor } \\
\hline RO & 151 & 68.5 & Reference & & & Reference & & \\
\hline R1 & 15 & 11.5 & 2.92 & $(1.48-5.73)$ & $<0.01$ & 2.11 & $(0.48-9.40)$ & 0.33 \\
\hline \multicolumn{9}{|c|}{ Postoperative complication $\geq$ CD ॥ } \\
\hline No & 121 & 68.5 & Reference & & & & & \\
\hline Yes & 45 & 44.8 & 1.46 & $(0.88-2.44)$ & 0.14 & & & \\
\hline \multicolumn{9}{|c|}{ Postoperative chemotherapy } \\
\hline No & 156 & 62.3 & Reference & & & & & \\
\hline Yes & 10 & $>83.4$ & 1.37 & $(0.55-3.41)$ & 0.50 & & & \\
\hline
\end{tabular}

Cardiac signs and chest radiography signs and respiratory history are classified according to the POSSUM scoring system. Pathological findings are provided according the Japanese classification of gastric carcinoma: 3rd English edition

${ }^{\text {a }}$ Distal gastrectomy includes one case with subtotal resection of remnant stomach

${ }^{\mathrm{b}}$ Total gastrectomy includes five cases with completion gastrectomy of remnant stomach

MST median survival time, HR hazard ratio, Cl confidence interval, ECOG-PS Eastern Cooperative Oncology Group Performance Status, ASA-PS American Society of Anesthesiologists physical status, PNI Onodera's prognostic nutritional index, POSSUM Physiological and Operative Severity Score for the enUmeration of Mortality and morbidity, COPD chronic obstructive pulmonary disease, $C D$ Clavien-Dindo

analysis revealed that ASA-PS 3,4, total or proximal gastrectomy, D0 lymphadenectomy, and pStage II-IV were independent risk factors for worse OS.

This result may mean that, among several parameters that may predict postoperative mortality, ASA-PS, while simple, is the keenest classification. A disadvantage of ASA-PS is that it can vary among evaluators even for the same patient. To address this, specific examples and explanations were added in 2014 as follows [9]. The definition of ASA-PS 3 is "a patient with severe systemic disease"; for example, poorly controlled diabetes mellitus or hypertension, chronic obstructive pulmonary disease, morbid obesity (body mass index $\geq 40$ ), active hepatitis, alcohol dependence or abuse, implanted pacemaker, moderate reduction of ejection fraction, end-stage renal disease undergoing regularly scheduled dialysis, history (>3 months) of myocardial infarction, cerebrovascular accident, transient ischemic attack, or coronary artery disease stents. Since this edition, ASA-PS has been evaluated relatively objectively. Which factor of ASA-PS influenced the prognosis was unclear in this study. Instead, we collected data on cardiac signs, chest radiography signs, and respiratory history to calculate the POSSUM physiological scores. Although these factors themselves were not prognostic factors, moderate or severe respiratory disease was associated with poor prognosis.

The extent of gastrectomy was an independent risk factor for mortality. Patients who underwent gastrectomy including the cardia (total, proximal, and completion gastrectomy) had shorter survival than those who underwent distal gastrectomy or subtotal resection of the remnant stomach. The former patients were more likely to die of pneumonia and senility (six and four among 48 patients, respectively) than were the latter patients (six and three among 105 patients, respectively), although no significant differences were found. Preserving the cardia may contribute to preventing regurgitation and malnutrition after gastrectomy. A previous report with patients aged $\geq 85$ years also mentioned that the prognosis of patients undergoing total gastrectomy was worse than that of patients after distal gastrectomy [18].

As well as the extent of gastrectomy, the extent of lymphadenectomy is also recommended to be limited in patients aged $\geq 80$ years [19]. A recent paper showed that D2 lymphadenectomy was an independent risk factor for postoperative pneumonia in patients aged $\geq 75$ years 
[20]. In our study, $\geq \mathrm{D} 2$ lymphadenectomy provided fair prognoses, and D1+ lymphadenectomy was also acceptable. However, D0 lymphadenectomy was an independent risk factor for worse OS compared with D2 lymphadenectomy, which may mean that excessively limited lymphadenectomy for advanced cancer is best avoided.

The pros and cons of adjuvant chemotherapy for gastric cancer in the elderly are also controversial. In the ACTSGC trial [21], which showed the effectiveness of S-1 adjuvant treatment for stage II or III gastric cancer, the eligibility criteria excluded patients aged over 80 years. In the current series, the number of patients who received postoperative chemotherapy was only $10(6 \%)$, which was too small for a statistical analysis. A questionnaire survey of JCOG also showed that only 99 (6.0\%) of 1660 gastrectomized patients aged $>80$ years received $\mathrm{S}-1$ adjuvant chemotherapy [22]. A phase III trial to confirm modified S-1 adjuvant chemotherapy for pathological stage II/ III vulnerable elderly gastric cancer patients after gastric resection (JCOG1507, BIRDIE) is ongoing [23], and the results are awaited.

The present study had several potential limitations. First, this study was limited by its retrospective nature. Second, some patients were not followed up for a sufficient period of time. Third, this study was conducted with a relatively small number of patients from two institutions. We would like to collect and reexamine more patients from more institutions in the future.

\section{Conclusion}

We retrospectively analyzed the prognostic factors for gastric cancer patients aged $\geq 80$ years after gastrectomy. The multivariate analyses showed that ASA-PS 3,4, gastrectomy including cardia, D0 lymphadenectomy, and pathological stage II-IV had worse prognoses. Gastrectomy for elderly patients with severe systemic disease should be carefully performed, and the gastric cardia should be preserved if possible.

\begin{abstract}
Abbreviations
ASA-PS: American Society of Anesthesiologists physical status; HR: Hazard ratio; Cl: Confidence interval; NCD: National Clinical Database; ECOG-PS: Eastern Cooperative Oncology Group performance status; POSSUM: Physiological and Operative Severity Score for the enUmeration of Mortality and morbidity; PNI: Prognostic nutritional index; OS: Overall survival.
\end{abstract}

\section{Acknowledgements}

The authors would like to thank Medical English Service for the English language review.

\section{Authors' contributions}

All authors have read and approved the manuscript. SE: protocol/project development, data collection, data analysis, and manuscript writing/editing. $T Y, Y F, M H, T K$, and $H M$ : data collection and management. $H T$, TO, and $K Y$ : manuscript writing/editing. KS and TU: protocol/project development and manuscript writing/editing.

Funding

This study was funded by Kawasaki Medical School.

Availability of data and materials

The datasets used and analyzed during this study are available from the corresponding author upon reasonable request.

\section{Declarations}

\section{Ethics approval and consent to participate}

The protocol for this research project was approved by the institutional review board of Kawasaki Medical School (approval number 5083-01) and conformed to the 1964 Helsinki Declaration and its later amendments or with comparable ethical standards. Written informed consent for surgery was obtained from patients as required by participating institutions. We used an opt-out recruitment strategy because the study exclusively analyzed retrospective clinical data without investigation by investigators.

\section{Consent for publication}

No applicable.

\section{Competing interests}

The authors declare that they have no conflict of interest to disclose.

\section{Author details}

${ }^{1}$ Department of Digestive Surgery, Kawasaki Medical School, 577 Matsushima, Kurashiki, Okayama 701-0192, Japan. ${ }^{2}$ Department of General Surgery, Kawasaki Medical School, Okayama, Japan. ${ }^{3}$ Department of Surgery, Mitsugi General Hospital, Hiroshima, Japan. ${ }^{4}$ Department of General Geriatric Medicine, Kawasaki Medical School, Okayama, Japan.

Received: 27 August 2021 Accepted: 13 December 2021

Published online: 07 January 2022

\section{References}

1. Population estimates by age (five-year groups) and sex. Statics Bureau of Japan, Tokyo. 2021. https://www.stat.go.jp/english/data/jinsui/tsuki/ index.html Accessed 17 May 2021.

2. Kakeji Y, Takahashi A, Hasegawa H, Ueno H, Eguchi S, Endo I, et al. Surgical outcomes in gastroenterological surgery in Japan: report of the National Clinical Database 2011-2018. Ann Gastroenterol Surg. 2020:4:250-74

3. Komori K, Kano K, Aoyama T, Hashimoto I, Hara K, Murakawa M, et al. The short- and long-term outcomes of gastrectomy in elderly patients with gastric cancer. In Vivo. 2020;34:2697-703.

4. Wong JU, Tai FC, Huang CC. An examination of surgical and survival outcomes in the elderly (65-79 years of age) and the very elderly ( 80 years of age) who received surgery for gastric cancer. Curr Med Res Opin. 2020;36:229-33.

5. Otowa Y, Okamoto S, Fujinaka R, Arai K, Murata K, Mii Y, et al. Feasibility and effectiveness of gastrectomy for elderly gastric cancer patients. In Vivo. 2019:33:1307-11.

6. Mengardo V, Cormack OM, Weindelmayer J, Chaudry A, Bencivenga M, Giacopuzzi S, et al. Multicenter study of presentation, management, and postoperative and long-term outcomes of septegenerians and octogenerians undergoing gastrectomy for gastric cancer. Ann Surg Oncol. 2018:25:2374-82.

7. Fujiwara Y, Fukuda S, Tsujie M, Ishikawa H, Kitani K, Inoue K, et al. Effects of age on survival and morbidity in gastric cancer patients undergoing gastrectomy. World J Gastrointest Oncol. 2017;9:257-62.

8. Oken MM, Creech RH, Tormey DC, Horton J, Davis TE, McFadden ET, et al. Toxicity and response criteria of the eastern cooperative oncology group. Am J Clin Oncol. 1982;5:649-55. 
9. ASA. Physical status classification system. Schaumburg: American Society of Anesthesiologists; 2020. https://www.asahq.org/standards-and-guide lines/asa-physical-status-classification-system Accessed 18 Nov 2021

10. Onodera T, Goseki N, Kosaki G. Prognostic nutritional index in gastrointestinal surgery of malnourished cancer patients (in Japanese). Nippon Geka Gakkai Zasshi (Journal of Japan Surgical Society). 1984;85:1001-5.

11. Copeland GP, Jones D, Walters M. POSSUM:a scoring system for surgical audit. Br J Surg. 1991;78:355-60.

12. Matsunaga T, Ishiguro R, Miyauchi W, Shishido Y, Miyatani K, Yamamoto $M$, et al. Appraisal of long-time outcomes after curative surgery in elderly patients with gastric cancer: a propensity score matching analysis. BMC Surg. 2021;21:33.

13. Kim SY, Kim JH, Chin H, Jun KH. Prediction of postoperative mortality and morbidity in octogenarians with gastric cancer - comparison of P-POSSUM, O-POSSUM, and E-POSSUM: a retrospective single-center cohort study. Int J Surg. 2020;77:64-8.

14. Gong CS, Yook JH, Oh ST, Kim BS. Comparison of survival of surgical resection and conservative treatment in patients with gastric cancer aged 80 years or older: a single-center experience. Ann Surg Treat Res. 2016:91:219-25.

15. Japanese Gastric Cancer Association. Japanese classification of gastric carcinoma: 3rd English edition. Gastric Cancer. 2011;14:101-12.

16. Japanese Gastric Cancer Association. Japanese gastric cancer treatment guidelines 2018 (5th edition). Gastric Cancer. 2021;24:1-21.

17. Dindo D, Demartines N, Clavien PA. Classification of surgical complications: a new proposal with evaluation in a cohort of 6336 patients and results of a survey. Ann Surg. 2004;240:205-13.

18. Endo $S$, Shimizu Y, Ikenaga M, Ohta K, Yamada T. Survival benefit of gastrectomy for gastric cancer in patients 85 years old: a retrospective propensity score-matched analysis. Surgery. 2017;161:984-94.

19. Katai H, Sasako M, Sano T, Maruyama K. The outcome of surgical treatment for gastric carcinoma in the elderly. Jpn J Clin Oncol. 1998;28:112-5.

20. Kimura R, Moriyama T, Ohuchida K, Shindo K, Nagai S, Ohtsuka T, et al. Risk factors for postoperative pneumonia after laparoscopic gastrectomy in patients aged 75 years and over with gastric cancer. Asian J Endosc Surg. 2021;14:408-16.

21. Sakuramoto S, Sasako M, Yamaguchi T, Kinoshita T, Fujii M, Nashimoto A, et al. Adjuvant chemotherapy for gastric cancer with S-1, an oral fluoropyrimidine. N Engl J Med. 2007;357:1810-20.

22. Tanahashi T, Yoshida K, Yamaguchi K, Okumura N, Takeno A, Fujitani K, et al. Questionnaire survey on adjuvant chemotherapy for elderly patients after gastrectomy indicates their vulnelabilities. Gastric Cancer. 2019;22:130-7.

23. Mizutani T, Yamaguchi K, Mizusawa J, Ito S, Nishida Y, Yabusaki H, et al. A phase III trial to confirm modified S-1 adjuvant chemotherapy for pathological stage II/III vulnerable elderly gastric cancer patients who underwent gastric resection (JCOG1507, BIRDIE). Jpn J Clin Oncol. 2018;48:1101-4.

\section{Publisher's Note}

Springer Nature remains neutral with regard to jurisdictional claims in published maps and institutional affiliations.

Ready to submit your research? Choose BMC and benefit from:

- fast, convenient online submission

- thorough peer review by experienced researchers in your field

- rapid publication on acceptance

- support for research data, including large and complex data types

- gold Open Access which fosters wider collaboration and increased citations

- maximum visibility for your research: over $100 \mathrm{M}$ website views per year

At BMC, research is always in progress.

Learn more biomedcentral.com/submissions 